\title{
Early peroxisome proliferator-activated receptor gamma regulated genes involved in expansion of pancreatic beta cell mass
}

\author{
Yurena Vivas ${ }^{1}$, Cristina Martínez-García', Adriana Izquierdo ${ }^{1}$, Francisco Garcia-Garcia², Sergio Callejas³, \\ Ismael Velasco ${ }^{1}$, Mark Campbell ${ }^{4}$, Manuel Ros ${ }^{1}$, Ana Dopazo ${ }^{3}$, Joaquin Dopazo ${ }^{2}$, Antonio Vidal-Puig ${ }^{4}$ and \\ Gema Medina-Gomez ${ }^{1 *}$
}

\begin{abstract}
Background: The progression towards type 2 diabetes depends on the allostatic response of pancreatic beta cells to synthesise and secrete enough insulin to compensate for insulin resistance. The endocrine pancreas is a plastic tissue able to expand or regress in response to the requirements imposed by physiological and pathophysiological states associated to insulin resistance such as pregnancy, obesity or ageing, but the mechanisms mediating beta cell mass expansion in these scenarios are not well defined. We have recently shown that ob/ob mice with genetic ablation of PPAR $\gamma 2$, a mouse model known as the POKO mouse failed to expand its beta cell mass. This phenotype contrasted with the appropriate expansion of the beta cell mass observed in their obese littermate ob/ob mice. Thus, comparison of these models islets particularly at early ages could provide some new insights on early PPARy dependent transcriptional responses involved in the process of beta cell mass expansion
\end{abstract}

Results: Here we have investigated PPAR $\gamma$ dependent transcriptional responses occurring during the early stages of beta cell adaptation to insulin resistance in wild type, ob/ob, PPARY2 KO and POKO mice. We have identified genes known to regulate both the rate of proliferation and the survival signals of beta cells. Moreover we have also identified new pathways induced in ob/ob islets that remained unchanged in POKO islets, suggesting an important role for PPAR in maintenance/activation of mechanisms essential for the continued function of the beta cell.

Conclusions: Our data suggest that the expansion of beta cell mass observed in ob/ob islets is associated with the activation of an immune response that fails to occur in POKO islets. We have also indentified other PPAR $\gamma$ dependent differentially regulated pathways including cholesterol biosynthesis, apoptosis through TGF- $\beta$ signaling and decreased oxidative phosphorylation.

\section{Background}

Although the hallmark of obesity associated type 2 diabetes (T2D) is the decrease in insulin sensitivity, the development of hyperglycemia requires the failure of the allostatic response of the $\beta$-cells to respond by producing enough insulin to overcome the functional defect in insulin action [1]. One of the strategies the endocrine pancreas uses to adapt to changes in insulin resistant requirements associated with different physiological

\footnotetext{
* Correspondence: gema.medina@urjc.es

'Universidad Rey Juan Carlos. Dpto. de Bioquímica, Fisiología y Genética

Molecular. Avda.de Atenas s/n. 28922. Alcorcón. Madrid. Spain

Full list of author information is available at the end of the article
}

states, such as pregnancy, obesity, or ageing, is to expand the $\beta$-cell mass. Thus, in all these states insulin resistance leads to an increased production of insulin to maintain euglycemia [2]. Despite the increased requirements, the majority of individuals remain euglycemic by adequately increasing their $\beta$-cell mass and by adjusting their stimulated insulin secretion. However, when the allostatic $\beta$-cell adaptation fails, hyperglycemia will develop. Under conditions of allostatic overload, there is an association between pregnancy with gestational diabetes and obesity and ageing with T2D [3].

In humans and animal models, it has been widely recognised that $\beta$-cell failure is an essential factor 
leading to T2D. This can occur when $\beta$-cells fail to appropriately expand and/or to optimise their function, ultimately compromising in glucose-stimulated insulin secretion (GSIS). Animal models of insulin resistance are excellent models to demonstrate the plasticity of $\beta$ cell mass and provide suitable experimental systems in which to identify the extracellular signals and molecular mechanisms behind this compensatory response.

Valuable insights into the key role of $\beta$-cell failure in the pathogenesis of T2D has come from genome-wide association studies, an important resource to identify new unexpected susceptibility gene candidates for the development of T2D [4]. Of interest these studies identified validated variants associated with insulin-secretory defects in the general population and showed little if any relationship to insulin resistance [5-9].

Peroxisome proliferator-activated receptor gamma (PPAR $\gamma$ ) is a member of the nuclear receptor superfamily of ligand-activated transcription factors [10] and has been shown to be involved in many diverse biological processes, including adipogenesis and glucose and lipid metabolism. In addition to these roles, it has been shown that PPAR $\gamma$ also exerts an important role in controlling cellular proliferation in different organs including pancreatic endocrine tissue. As already demonstrated, the absence of PPAR $\gamma$ specifically in $\beta$ cells cannot fully compensate for the $\beta$-cell dysfunction seen in states of peripheral insulin resistance [11]. In fact, animals with lack of PPAR $\gamma$ had blunted the physiological expansion of $\beta$-cell mass in response to highfat feeding.

There are important differences between the mechanisms controlling the increase of $\beta$-cell mass observed during pregnancy and obesity suggesting certain degree of etiopathogenic specificity on the mechanisms controlling $\beta$-cell mass expansion [12-15]. We have recently shown that $\beta$-cell mass adaptation to insulin resistance failed in the adult POKO mice, an insulin resistant mouse resulting from the deletion of PPAR $\gamma 2$ in an obese ob/ob background [16]. This impaired $\beta$-cell mass expansion contrasted with the massive expansion observed in their obese littermate ob/ob mice. Thus, we rationalised that comparison of $\mathrm{ob} / \mathrm{ob}$ and $\mathrm{POKO}$ mice islets particularly at early ages could provide some new insights on early PPAR $\gamma$ dependent transcriptional responses involved in the process of $\beta$-cell mass expansion.

To date, the main approach to identifying global transcriptional changes has been the use of gene expression microarray platforms in advanced stages of the disease. Here we focused in early evolutive stages to increase our chances of identifying novel early events and their molecular effectors involved in the adaptation of $\beta$-cells to insulin resistance. Our strategy has been to isolate total RNA samples from islets of 5-week-old female wild type (WT), PPAR $\gamma 2 \mathrm{KO}, \mathrm{ob} / \mathrm{ob}$ and POKO mice for large-scale expression profiling. We have used 5-weekold mice to elucidate pathways and factors underlying the early islet proliferative response that might have failed in the POKO mice and that could cause the inadequate $\beta$-cell expansion in this model. Although at this age metabolic disturbances have not been identified in islets yet, insulin resistance is already detectable in $\mathrm{ob} / \mathrm{ob}$ and POKO mice. In support of this approach we have shown that defects in proliferation markers can be detected at 5 weeks of age in POKO islets, well before alterations in the insulin secretory capacity were evident [17].

Initially, we have analyzed genes to compare ob/ob with WT mice. This comparison should identify any gene regulation in ob/ob mice that may be linked to the increased expansion of their $\beta$-cells. Secondly, we have compared POKO vs. WT islets. As these two models have a similar degree of expansion of their $\beta$-cells, the aim was to identify default genes induced during insulin resistance that were dependent on PPAR $\gamma 2$ activity. In our previous study [17] we have shown that at 16 weeks of age, despite being more insulin resistant than ob/ob mice, the $\beta$-cell mass of POKO mice remained similar to that of WT islets. This resulted in POKO mice having an inappropriately lower insulin plasma level than the ob/ob controls at 16 weeks of age [18]. The final comparison that we have analyzed was between POKO and ob/ob islets, representing different states of insulin resistance that could identify PPAR $\gamma$-dependent genes involved in expansion and function of $\beta$-cell.

In this study we have identified genes that are downregulated in PPAR $\gamma$-deficient POKO islets that are related to the proliferation and survival mechanisms that may facilitate the expansion of $\beta$-cell mass under insulin resistant conditions. We have also identified new pathways that may contribute to this adaptation such as immune response, cholesterol biosynthesis, apoptosis through TGF- $\beta$ signaling pathway and decreased oxidative phosphorylation. Failure of these adaptive mechanisms may contribute to failure of $\beta$-cell function in POKO islets and may be dependent on PPAR $\gamma$ expression and functionality.

\section{Results}

Total RNA was extracted from islets obtained from 5week-old female WT, PPAR $\gamma 2 \mathrm{KO}$, ob/ob and POKO mice and used for microarray analysis. The number of genes differentially expressed amongst the specific comparisons for an adjusted $p$-value $\leq 0.05$, (unless otherwise specified), are shown in table 1 and the interactions between the diverse comparisons are shown in Figure 1. 
Table 1 Differential expressed genes amongst the specific comparisons

\begin{tabular}{|c|c|c|c|c|c|c|}
\hline & ob/ob vs. WT & PPAR $\gamma 2 K O$ vs WT & POKO vs. WT & ob/ob vs. PPARү2KO & POKO vs. ob/ob & POKO vs. PPAR $\gamma 2 K O$ \\
\hline Down & 2349 & $7(p \leq 0.2)$ & 51 & 23 & $1(p \leq 0.3)$ & $81(p \leq 0.2)$ \\
\hline Up & 2532 & $26(p \leq 0.2)$ & 527 & 30 & $3(p \leq 0.3)$ & $85(p \leq 0.2)$ \\
\hline
\end{tabular}

Number of differentially expressed genes amongst the specific comparisons for an adjusted p-value $\leq 0.05$ and log FC $\geq 1$, unless are specified.

\section{Differential gene expression between wild type and ob /ob mice islets}

We have previously shown that ob/ob mice have increased number and size of islets compared with their WT littermates $[17,18]$, a difference that becomes more obvious as these mice age and become more metabolically compromised. Based on these observations, we hypothesised that the comparison between WT and ob/ ob islets at a young age may identify early initial changes in islet gene expression associated with or leading to $\beta$-cell mass expansion (Table 2).

As expected the comparison between islets from ob/ ob and WT mice identified many of the genes previously identified that play a role in $\beta$-cell expansion during states of insulin resistance such as obesity and pregnancy [15]. These positive controls included genes involved in proliferation, cell cycle and survival mechanisms [19]. For instance, gene expression levels of cyclin A2, B1, D1 and D3 were significantly increased in islets from ob/ob compared with WT mice. Conversely expression of cell division protein kinase 6 (Cdk6) and Cdk7 were significantly decreased in the ob/ob compared to WT islets. This transcriptional pattern closely mirrors the pattern observed during the $\beta$-cell

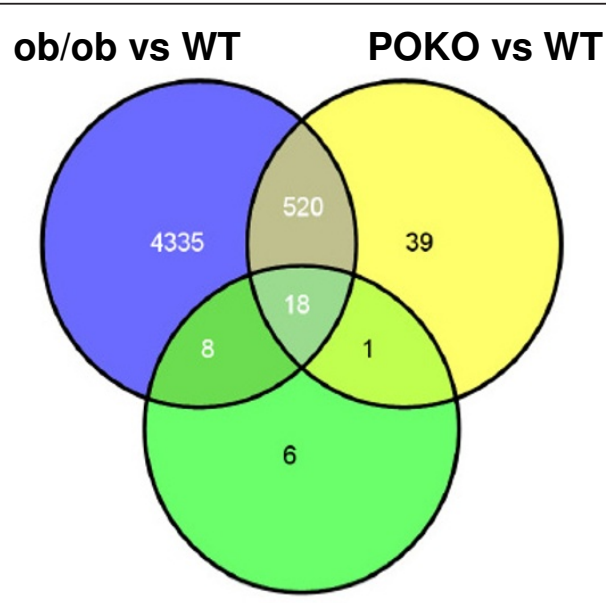

\section{PPAR $\gamma 2 K O$ vs WT}

Figure 1 A venn diagram showing relations between differentially expressed genes. A venn diagram showing relations between differentially expressed genes ( $\log F C \geq 1$; Adj. P-value $\leq 0.05)$ in the comparisons ob/ob vs. WT, POKO vs. WT and PPARy2KO vs. WT mice. hypertrophy typically associated with pregnancy, suggesting these genes are part of a common proliferative response associated with modulation of $\beta$-cell mass in physiological and pathophysiological states. Our analysis also confirmed the upregulation of genes encoding for enzymes involved in regulation of $\beta$-cell expansion (IL2inducible T-cell kinase (Itk), Tumor necrosis factor receptor superfamily, member $11 \mathrm{~b}$ (osteoprotegerin or Tnfrsf11b), baculoviral IAP repeat containing 5 (Birc5)) and cell cycle regulation (F-box and leucine-rich repeat protein 14 (Fbxw14), Fbxl21 and F-box protein 27 (Fbxo27)). Globally, these data indicate that at this early age the ob/ob islets have already activated their proliferative machinery and this data can be considered as a positive quality control for the experiment.

\section{Differential gene expression between WT and POKO islets} We next compared the gene expression profile between POKO and WT islets (Table 2). Since the POKO mouse fails to expand its $\beta$-cell mass despite insulin resistance, we hypothesized that this list may reveal by default genes induced during insulin resistance that were dependent on PPAR $\gamma 2$ activity. Our first observation was that POKO and WT islets had a very similar gene expression profile. In fact the expression of many of the genes previously shown to be dysregulated in ob/ ob islets were not significantly different in the analysis comparing POKO and WT islets. This is consistent with the maintenance of "normal" $\beta$-cell mass in POKO mice that fail to expand. However, through more detailed analysis, it revealed that despite the inability to expand their $\beta$-cell mass, POKO islets had induction of some of recognized mediators of $\beta$-cell expansion, as observed during both pregnancy and obesity. These included Tnfrsf11b, mKi67, Surfactant-associated protein D (Sftpd) and Free fatty acid receptor 2 (Ffar2). These genes were increased in both the comparison between ob/ob vs. WT, and also to a lesser extent in the comparison between POKO vs. WT. These data suggested a dysregulation of the homeostatic control of $\beta$-cell mass in POKO islets, and that the ability of POKO mice to appropriately induce an appropriate response to a metabolic stress is impaired, with no increased proliferation and activation of survival mechanisms in their islets. Globally considered, this indicates a partial response of PPAR $\gamma$-deficient ob/ob islets to insulin resistance. 
Table 2 Differential gene expression between WT and ob/ob islets and between WT and POKO islets

\begin{tabular}{|c|c|c|c|c|}
\hline \multicolumn{5}{|c|}{$\begin{array}{l}\text { Comparison WT vs. } \\
\text { ob/ob }\end{array}$} \\
\hline$\overline{\text { Name }}$ & Symbol & Description & Log FC & $\begin{array}{l}\text { Adj } p- \\
\text { value }\end{array}$ \\
\hline NM_009828 & Ccna2 & cyclin A2 (Ccna2), mRNA & 1.062995 & 0.037082104 \\
\hline NM_172301 & Ccnb1 & cyclin B1 (Ccnb1), mRNA & 1.093047367 & 0.033661413 \\
\hline S78355 & Cond 1 & Cyl-1 = cyclin D1 [mice, BALB/c, brain, mRNA, 3737 nt]. & 0.814358 & 0.060937249 \\
\hline NM_007632 & Ccnd3 & cyclin D3 (Ccnd3), transcript variant 1, mRNA & 0.537596 & 0.081161755 \\
\hline NM_178674 & $\mathrm{Fbxl} 21$ & F-box and leucine-rich repeat protein 21 (Fbx|21), mRNA & 1.379136 & 0.021465994 \\
\hline NM_207238 & $\mathrm{FbxO} 27$ & F-box protein 27 (Fbxo27), mRNA & 1.251021 & 0.024989279 \\
\hline NM_010583 & Itk & Mus musculus IL2-inducible T-cellkinase (Itk), mRNA & 4.9433924 & 0.016907267 \\
\hline NM_008764 & Tnfrsf11b & tumor necrosis factor receptor superfamily, member $11 \mathrm{~b}$ (osteoprotegerin) (Tnfrsf1 1b), mRNA & 2.137707 & 0.00427033 \\
\hline NM_009689 & Birc5 & baculoviral IAP repeat-containing 5 (Birc5), transcript variant 1, mRNA & 0.749711 & 0.0488386 \\
\hline NM_015793 & Fbxw14 & F-box and WD-40 domain protein 14 (Fbxw14), mRNA [NM_015793] & 2.053845 & 0.020165243 \\
\hline NM_009873 & Cdk6 & cyclin-dependent kinase 6 (Cdk6), mRNA & -1.44108 & 0.011012 \\
\hline AK145759 & Cdk7 & $\begin{array}{l}\text { blastocyst cDNA, RIKEN full-length enriched library, clone:11C0038J11 product:cyclin-dependent } \\
\text { kinase } 7 \text { (homolog of Xenopus MO15 cdk-activating kinase), full insert sequence }\end{array}$ & -1.18402 & 0.009851 \\
\hline \multicolumn{5}{|c|}{$\frac{\text { Comparison WT vs. }}{\text { POKO }}$} \\
\hline Name & Symbol & Description & Log FC & $\begin{array}{l}\text { Adj } p- \\
\text { value }\end{array}$ \\
\hline NM_008764 & Tnfrsf11b & tumor necrosis factor receptor superfamily,member $11 \mathrm{~b}$ (osteoprotegerin)(Tnfrsf11b), mRNA & 1.4263697 & 0.028955326 \\
\hline X82786 & mKi67 & mRNA for Ki-67. & 1.5311213 & 0.026624778 \\
\hline NM_009160 & Sftpd & surfactant associated protein D (Sftpd), mRNA & 2.10936363 & 0.04279018 \\
\hline NM_146187 & Ffar2 & free fatty acid receptor 2 (Ffar2), mRNA & 1.371649 & 0.033601951 \\
\hline
\end{tabular}

\section{Differential gene expression between ob/ob and POKO mice}

We hypothesized that the POKO vs. ob/ob comparison could identify PPAR $\gamma 2$ islet target genes that were dysregulated during the early stages of insulin resistant states contributing to a lack of $\beta$-cell mass expansion. We have previously shown that at 16 weeks of age POKO mice have significantly decreased islet number and mass compared to ob/ob mice and more interestingly, the number and size of islets in POKO mice resembled the number and size of the islets of a wild type 16-week-old mouse $[17,18]$. Analysis of gene expression by RT-PCR showed that at 5 weeks of age, there were already some changes in the expression of specific genes relating to proliferation (CyclinD1) and $\beta$-cell function (Insulin, MafA, PDX1 and Glut 2), with no evident differences in insulin secretory defects between POKO and ob/ob [17]. However, differences in gene expression of other genes, which have been shown at 16 weeks were inconsistent at this age. Surprisingly the comparison between 5week-old ob/ob and POKO islets on microarray data only identified 3 upregulated genes, (Actin alpha1 (Acta1), Thrombospondin 4 (Thbs4) and Solute carrier family 5 (sodium/glucose cotransporter) (Slc5a10), and as expected, down regulation of gene PPAR $\gamma$ with an adjusted $\mathrm{p}$-value $\leq 0.3$ (Table 1 ). To allow a more detailed comparison between our models, we performed pathway analysis using Fatigo and FatiScan tools, enabling significant multiple comparisons of genes in significant pathways despite not having differentially specific expressed genes from these pathways at this early age.

\section{Dysregulated gene expression pathway analysis in models with different degree of beta cell expansion}

A subsequent post-analysis was performed on the microarray data from the comparison between 5-weekold islets in order to identify the main dysregulated pathways, relating to the expansion of $\beta$-cells between the three genotypes. For this we have used two bioinformatic tools: the Ingenuity Pathway Analysis (IPA) and gene enrichment test from Babelomics tools (Fatigo), using an adjusted $\mathrm{p}$ value $\leq 0.05$. To allow reliable interpretation of our data we have made the following comparisons: ob/ob vs. WT; associated with the normal adaptation to obesity induced insulin resistance with an expansion of the $\beta$-cell; and POKO vs. WT; associated with a failure in the adaptive response, with no expansion of $\beta$-cell. Using these two lists, we analyzed upregulated and down-regulated genes from the comparison between ob/ob and WT, which were not regulated between POKO and WT.

First we analyzed the list of significantly up-regulated genes in islets from the comparison between ob/ob and 
WT mice that were not significantly changed in the comparison between POKO and WT mice. This was hypothesised to identify genes that were up regulated during $\beta$-cell expansion during obesity in the case of the $\mathrm{ob} / \mathrm{ob}$, which failed to occur in a PPAR $\gamma$-dependent model such as the POKO mouse. Up regulated functions scored are based on the number of Network Eligible molecules they contain the top associated disease and disorders networks of up regulated genes from IPA for this first comparison were: immunological disease, inflammatory disease and inflammatory response. Other top networks scored for this comparison are presented in table 3. Cellular Development, and Cellular Function and Maintenance were identified as the first top molecular and cellular function networks. Cell morphology, proliferation and development were also in this first comparison. Similarly, the top five canonical pathways that they were significant up-regulated included Autoimmune Thyroid Disease Signalling, Allograft Rejection
Signalling and more importantly Type 1 Diabetes Mellitus Signalling (Table 3).

Overall these results demonstrate that $\beta$-cell mass expansion in the context of obesity brings about a subtle, but coordinated increase in the basal level of a wide array of genes involved in the inflammatory and autoimmune response of ob/ob islets that does not occur in PPAR $\gamma 2$-ablated POKO islets. This concept was supported by the identification of specific molecules relating to antigen processing and antigen-presenting signalling such as MHC class II molecules and CD80/86 that were increased in the ob/ob vs. WT comparison and not the POKO vs. WT. Our analysis has also identified genes in these pathways such as granzyme B and perforin 1 , with newly recognized roles in inflammation that have also been implicated in antigen presentation to cells, and genes such as granulophilin, which is involved in insulin secretion. Using databases of genome-wide regulatory module and element predictions

Table 3 Functions and canonical pathways as differentially expressed up-regulated genes in ob/ob vs. WT, with no significant changes in POKO vs. WT mice

\begin{tabular}{|c|c|c|}
\hline \multicolumn{3}{|l|}{ Top Bio Functions } \\
\hline Name & p-value & \# Molecules \\
\hline \multicolumn{3}{|l|}{ Diseases and Disorders } \\
\hline Immunological Disease & 7.66E-18 - 3.63E-03 & 250 \\
\hline Inflammatory Disease & $5.95 \mathrm{E}-15-3.60 \mathrm{E}-03$ & 263 \\
\hline InflammatoryResponse & $2.28 \mathrm{E}-14-3.63 \mathrm{E}-03$ & 144 \\
\hline Skeletal and Muscular Disorders & 4.99E-12-3.63E-03 & 255 \\
\hline Connective Tissue Disorders & $7.78 \mathrm{E}-12-2.44 \mathrm{E}-03$ & 175 \\
\hline \multicolumn{3}{|l|}{ Molecular and Cellular Functions } \\
\hline Cellular Development & $1.45 \mathrm{E}-17-4.37 \mathrm{E}-03$ & 197 \\
\hline Cellular Function and Maintenance & $2.21 \mathrm{E}-15-3.58 \mathrm{E}-03$ & 103 \\
\hline Cell-To-Cell Signaling and Interaction & $9.41 \mathrm{E}-15-4.37 \mathrm{E}-03$ & 202 \\
\hline Cellular Growth and Proliferation & $3.93 \mathrm{E}-13-3.11 \mathrm{E}-03$ & 173 \\
\hline Cellular Movement & $1.94 \mathrm{E}-09-3.78 \mathrm{E}-03$ & 143 \\
\hline \multicolumn{3}{|l|}{ Physiological System Development and Function } \\
\hline Hematological System Development and Function & $3.63 \mathrm{E}-16-4.04 \mathrm{E}-03$ & 189 \\
\hline Hematopoiesis & $3.63 \mathrm{E}-16-3.27 \mathrm{E}-03$ & 112 \\
\hline Tissue Morphology & $2.59 \mathrm{E}-15-3.60 \mathrm{E}-03$ & 124 \\
\hline Cell-mediated Immune Response & $1.22 \mathrm{E}-14-3.78 \mathrm{E}-03$ & 92 \\
\hline Immune Cell Trafficking & $2.25 \mathrm{E}-13-3.78 \mathrm{E}-03$ & 118 \\
\hline \multicolumn{3}{|l|}{ Top Canonical Pathways } \\
\hline Name & p-value & Ratio \\
\hline Autoimmune Thyroid Disease Signaling & $3.06 \mathrm{E}-13$ & $17 / 61(0.279)$ \\
\hline Allograft Rejection Signaling & $1.49 \mathrm{E}-12$ & $16 / 59(0.271)$ \\
\hline Type I Diabetes Mellitus Signaling & $4.79 \mathrm{E}-12$ & $27 / 119(0.227)$ \\
\hline Graft-versus-Host Disease Signaling & $3.57 \mathrm{E}-10$ & $15 / 49(0.306)$ \\
\hline B Cell Development & $8.43 \mathrm{E}-10$ & $12 / 37(0.324)$ \\
\hline
\end{tabular}

Functions and canonical pathways identified by IPA as differentially expressed up regulated genes in islets from ob/ob vs. WT mice (fold change $\geq 1 ; \mathrm{P} \leq 0.05$ ), with no significant changes in islets from POKO vs. WT mice.

Note: $p$ value was calculated using the Benjamini-Hochberg method of multiple testing correction. In the case of canonical pathways "Ratio" indicates the number of differentially expressed genes in a given pathway, divided by total number of genes that make up that pathway. 
(cisRED), we have identified a PPAR conserved sequence motif in the perforin 1 sequence and by validating decreased expression of granulophilin by RT-PCR in PPAR $\gamma 2$-ablated mice (Figure 2), it suggests a possible PPAR $\gamma$ dependent pathway.

We have also analysed genes that were down regulated in $\mathrm{ob} / \mathrm{ob}$ islets when compared to WT, that were not significantly changed in the comparison between POKO and WT mice (Table 4). Genetic and Developmental
Disorder, Dermatological and Gastrointestinal Disease were scored as top associated networks in this comparison, but organ development, growth and proliferation were also included in these networks. Significantly down regulated functions in this comparison were Lipid Metabolism, Small Molecule Biochemistry and Vitamin and Mineral Metabolism (Table 4). Expression of Tocopherol (alpha) transfer protein (TTPA), member RAS oncogene family (RAB27B), Acyl-CoA thioesterase 5 (ACOT5) and

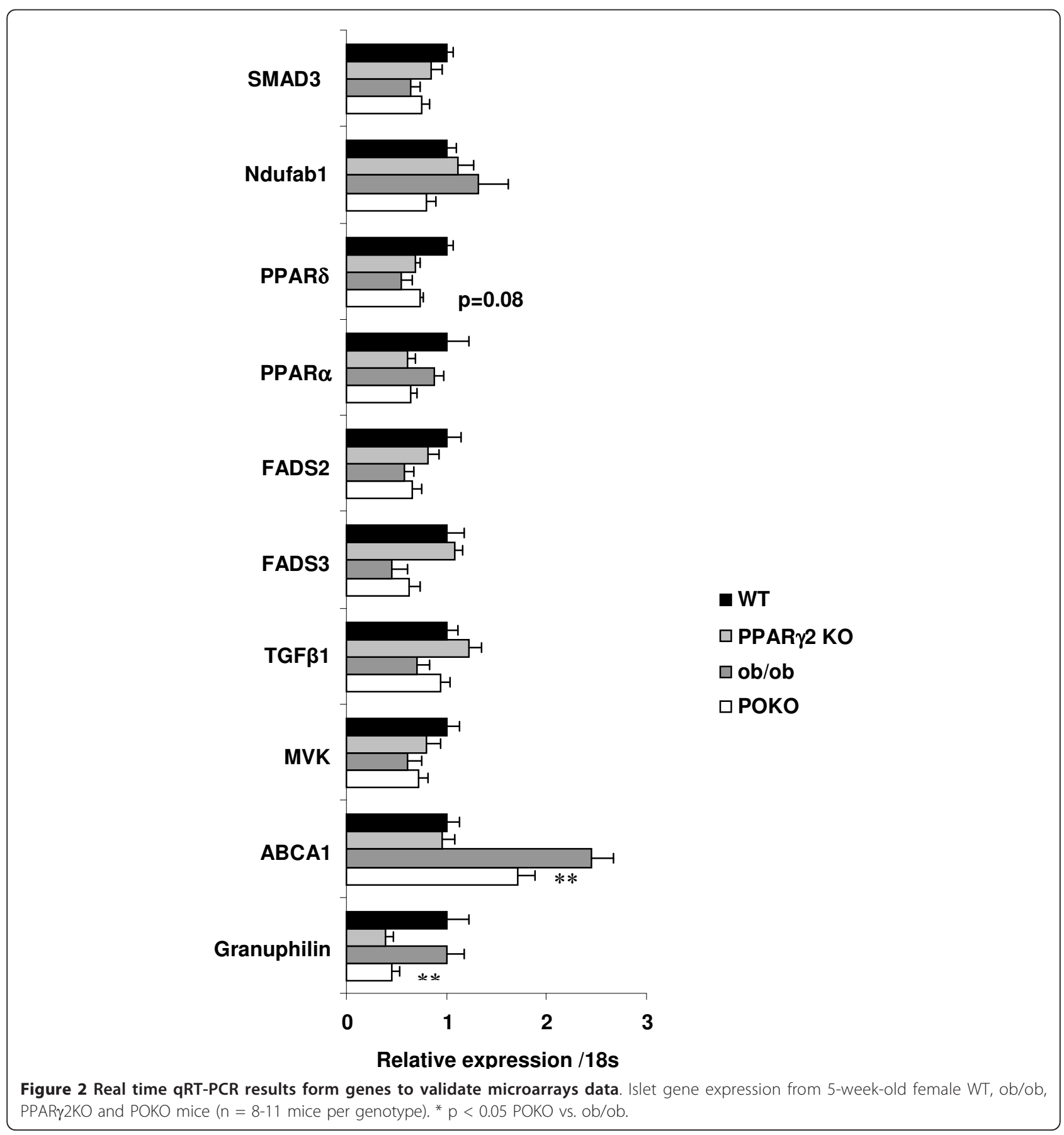


Hydroxysteroid (17-beta) dehydrogenase 14 (HSD17B14) were the most downregulated in ob/ob vs. WT, without changes between POKO vs. WT. Interestingly, we also identified a subset of genes from the canonical pathway of sterol biosynthesis including Mevalonate (diphospho) decarboxylase (MVD), Farnesyl diphosphate synthase (FDPS), Prenyldiphosphate synthase, subunit 1 (PDSS1), Isopentenyl-diphosphate delta isomerase 1 (IDI1), Cytochrome c oxidase 10 (COX10), Mevalonate kinase (MVK) and Fatty acid desaturase 3 (FADS3) to be significantly downregulated in ob/ob vs. WT, without changing in the comparison between POKO vs. WT (Table 4 and Figure 2).

We performed a gene enrichment test from Babelomics tools (Fatigo) on our data where significantly up and down-regulated groups of functionally related genes were identified from all expressed genes according to differential expression between the two comparisons (with higher or lower expression in ob/ob vs. WT but without changes in POKO vs. WT mice). Among the
1381 up-regulated genes in ob/ob vs. WT we identified 6 significantly (Adj. p-value $\leq 0.05$ ) overrepresented GO terms, 11 InterPro and 9 KEGG pathways. Among the 957 down-regulated genes we identified 11 significantly (Adj. p-value $\leq 0.05$ ) overrepresented GO terms and 3 KEGG pathways. Subsets of the functional groups are shown in Table 5, 6 and 7 and were chosen to include all significant (Adj. p-value $\leq 0.05$ ) KEGG pathways, InterPro and all significant overrepresented functional groups satisfying GO. Confirming our initial data from IPA, there was an up-regulation of GO terms involved in the immune response and antigen binding such as the KEGG pathway positive regulation of immune response in ob/ob vs. WT, without any change in POKO vs. WT islets. The down-regulated functional groups in ob/ob vs. WT without any change in POKO vs. WT islets were mainly associated with structural genes and cell-junctions (See Additional file 1 Figure S1). Consistent with our previous data, we identified down-regulated cholesterol and sterol biosynthetic

Table 4 Functions and canonical pathways as differentially expressed down-regulated genes in ob/ob vs. WT, with no significant changes in POKO vs. WT mice

\begin{tabular}{|c|c|c|}
\hline \multicolumn{3}{|l|}{ Top Bio Functions } \\
\hline Name & p-value & \# Molecules \\
\hline \multicolumn{3}{|l|}{ Diseases and Disorders } \\
\hline Dermatological Diseases and Conditions & $3.01 \mathrm{E}-05-4.21 \mathrm{E}-02$ & 37 \\
\hline Genetic Disorder & $3.01 \mathrm{E}-05-4.21 \mathrm{E}-02$ & 91 \\
\hline Cancer & $9.80 \mathrm{E}-05-4.21 \mathrm{E}-02$ & 170 \\
\hline Developmental Disorder & $6.95 \mathrm{E}-04-4.21 \mathrm{E}-02$ & 11 \\
\hline Gastrointestinal Disease & $1.48 \mathrm{E}-03-4.21 \mathrm{E}-02$ & 71 \\
\hline \multicolumn{3}{|l|}{ Molecular and Cellular Functions } \\
\hline Lipid Metabolism & $4.46 \mathrm{E}-07-4.21 \mathrm{E}-02$ & 50 \\
\hline Small Molecule Biochemistry & 4.46E-07 - 4.21E-02 & 71 \\
\hline Vitamin and Mineral Metabolism & 4.46E-07 - 4.21E-02 & 23 \\
\hline Cell-To-Cell Signaling and Interaction & $1.48 \mathrm{E}-04-4.21 \mathrm{E}-02$ & 63 \\
\hline Cellular Assembly and Organization & $1.48 \mathrm{E}-04-4.21 \mathrm{E}-02$ & 46 \\
\hline \multicolumn{3}{|l|}{ Physiological System Development and Function } \\
\hline Tumor Morphology & $9.80 \mathrm{E}-05-4.21 \mathrm{E}-02$ & 22 \\
\hline Hair and Skin Development and Function & 1.37E-03 - 4.21E-02 & 26 \\
\hline Organ Development & 1.37E-03 - 4.18E-02 & 35 \\
\hline Digestive System Development and Function & $1.50 \mathrm{E}-03-1.95 \mathrm{E}-02$ & 11 \\
\hline Organismal Development & $1.50 \mathrm{E}-03-4.18 \mathrm{E}-02$ & 26 \\
\hline \multicolumn{3}{|l|}{ Top Canonical Pathways } \\
\hline Name & p-value & Ratio \\
\hline Biosynthesis of Steroids & $1.96 \mathrm{E}-04$ & $7 / 128(0.055)$ \\
\hline HER-2 Signaling in Breast Cancer & $3.41 \mathrm{E}-03$ & 9/79 (0.114) \\
\hline Tight Junction Signaling & $9.59 \mathrm{E}-03$ & $13 / 167(0.078)$ \\
\hline Fatty Acid Biosynthesis & $1.23 \mathrm{E}-02$ & $3 / 51(0.059)$ \\
\hline ERK5 Signaling & $1.26 \mathrm{E}-02$ & 7/71 (0.099) \\
\hline
\end{tabular}

Functions and canonical pathways identified by IPA as differentially expressed down regulated genes in islets from ob/ob vs. WT mice (fold change $\geq 1 ; \mathrm{P} \leq$ 0.05), with no significant changes in islets from POKO vs. WT mice.

Note: p-value was calculated using the Benjamini-Hochberg method of multiple testing correction. In the case of canonical pathways "Ratio" indicates the number of differentially expressed genes in a given pathway, divided by total number of genes that make up that pathway. 
Table 5 KEGG significant terms up-regulated in ob/ob vs. WT, without significant changes in POKO vs. WT mice

\begin{tabular}{llccc}
\hline Term & Name & Term size & Odds ratio log & Adj. $\mathbf{p}$-value \\
\hline mmu00604 & Glycosphingolipid biosybthesis & 21 & 1.86 & $2.43 \mathrm{E}-02$ \\
mmu04940 & Type 1 diabetes & 54 & 1.83 & $2.96 \mathrm{E}-05$ \\
mmu05330 & Allograt rejection & 48 & 1.79 & $1.24 \mathrm{E}-04$ \\
mmu05332 & Graft-verus host disease & 50 & 1.74 & $1.63 \mathrm{E}-04$ \\
mmu05320 & Autoinmune thyroid disease & 63 & 1.71 & $3.08 \mathrm{E}-05$ \\
mmu04514 & Cell adhesion molecules & 141 & 1.65 & $2.05 \mathrm{E}-10$ \\
mmu05416 & Viral myocarditis & 80 & 1.23 & $5.78 \mathrm{E}-03$ \\
mmu04730 & Long term depresion & 74 & 1.14 & $2.51 \mathrm{E}-02$ \\
mmu04270 & Vascular smooth muscle contact & 126 & 1.12 & $1.43 \mathrm{E}-03$ \\
\hline
\end{tabular}

KEGG significant terms up-regulated in islets from ob/ob vs. WT mice (adjusted p-value $\leq 0.05$ ), without significant changes in islets from POKO vs. WT mice.

process and glutamine transport in the overrepresented GO terms in the comparison ob/ob vs. WT, without any significant difference in POKO vs. WT mice (Table 8 and Additional file 1 Figure S2).

\section{Functional profiling of differentially expressed genes in POKO mice that may contribute towards failure to expand beta cell mass}

We performed FatiScan analysis in the comparison between POKO and ob/ob islets obtained from our microarray. This FatiScan analysis highlights the value of using functional analysis, which incorporates all experimental data rather than limiting interpretation to those genes that rank among the highly differentially expressed. Using the FatiScan tool, 616 gene ontology groups, 85 InterPro, 67 KEGG pathways, 7 Biocarta, and 3 JasparTBS were observed to be significantly (adj. p value $\leq 0.05$ ) overrepresented in islets from POKO relative to the ob/ob mice. There was a substantial overlap of genes within these identified functional groups resulting in the overrepresentation of a large number of functionally similar gene ontology groups. Therefore only the highly expressed groups have been shown in tables.

Initially, an overrepresentation of genes related to biological processes such as neutral lipid catabolic process, lipid glycosilation, collagen biosynthesis process and regulation of actin filament length were identified. Analysis from FatiScan also identified genes related to mitochondrial outer and inner membrane translocase complex and fibrillar collagen in the cellular component group and profilin, lipoic acid and IgG binding in the molecular function group. Other molecular functions associated with highly expressed genes in POKO islets compared with ob/ob were RPTP-like protein binding, plateletderived growth factor binding and nucleocytoplasmic transporter activity. Genes from terms associated to Chaperonin TCP-1, Mob/phocein, hexokinase were identified as domains in InterPro.

The most significant KEGG pathways identified in the FatiScan functional analysis of genes with higher expression in POKO compared to ob/ob islets were the olfactory transduction and spliceosome (Table 9). Although no significant differences in singular genes were detected between both genotypes, this analysis found that there was increased expression of pathways with genes related to the formation of cellular junctions between cells as regulation of actin cytoskeleton, tight, adherence and gap junction. Pathways identified with increased gene expression in POKO compared to ob/ob islets also included terpenoid backbone, glutathione

Table 6 InterPro significant terms up-regulated in ob/ob vs. WT, without significant changes in POKO vs. WT mice

\begin{tabular}{ccccc}
\hline Term & Name & Term size & Odds ratio log & Adj. pvalue \\
\hline IPR006116 & 2-5-oligoadenylate synthetase, ubiquitin-like region (IPR006116) & 14 & 2.49 & $1.88 \mathrm{E}-02$ \\
IPR000342 & Regulator of G protein signalling (IPR000342) & 36 & 1.68 & $3.76 \mathrm{E}-02$ \\
IPR003597 & Immunoglobulin C1-set (IPR003597) & 93 & 1.62 & $5.28 \mathrm{E}-06$ \\
IPR006907 & Protein of unknown function DUF622 (IPR006907) & 73 & 1.51 & $1.05 \mathrm{E}-03$ \\
IPR003596 & Immunoglobulin V-set, subgroup (IPR003596) & 276 & 1.24 & $8.33 \mathrm{E}-09$ \\
IPR013151 & Immunoglobulin (IPR013151) & 364 & 1.22 & $3.35 \mathrm{E}-11$ \\
IPR003006 & Immunoglobulin/major histocompatibility complex, conserved site (IPR003006) & 90 & 1.17 & $4.29 \mathrm{E}-02$ \\
IPR007110 & Immunoglobulin-like (IPR007110) & 488 & 1.17 & $3.81 \mathrm{E}-13$ \\
IPR013106 & Immunoglobulin V-set (IPR013106) & 330 & 1.15 & $1.25 \mathrm{E}-08$ \\
IPR003599 & Immunoglobulin subtype (IPR003599) & 341 & 1.01 & $2.36 \mathrm{E}-08$ \\
IPR003598 & Immunoglobulin subtype 2 (IPR003598) & 371 & 0.89 \\
\hline
\end{tabular}

InterPro significant terms up-regulated in islets from ob/ob vs. WT mice (adjusted p-value $\leq 0.05$ ), without significant changes in islets from POKO vs. WT mice. 
Table 7 GO significant terms up-regulated in ob/ob vs. WT, without significant changes in POKO vs. WT mice

\begin{tabular}{cccc}
\hline Name & Term size & Odds ratio log & Adj. pvalue \\
\hline $\begin{array}{c}\text { GO molecular function } \\
\text { antigen binding (GO:0003823) }\end{array}$ & 23 & 2.87 & $1.136 \mathrm{E}-06$ \\
GO cellular component & & & $1.48 \mathrm{E}-07$ \\
cell surface (GO:0009986) & 365 & 0.91 & $2.38 \mathrm{E}-11$ \\
external side of plasma membrane (GO:0009897) & 190 & 1.41 & $6.95 \mathrm{E}-07$ \\
guanylate cyclase complex, soluble (GO:0008074) & 5 & 1.8 & $7.288 \mathrm{E}-06$ \\
GO biological process & & 0.83 & $4.08 \mathrm{E}-003$ \\
immune response (GO:0006955) & 599 & 2.93 & 13 \\
peptide hormone processing (GO:0016486)
\end{tabular}

GO significant terms up-regulated in islets from ob/ob vs. WT mice (adjusted p-value $\leq 0.05$ ), without significant changes in islets from POKO vs. WT mice.

metabolism, TGF- $\beta$ signalling and steroid biosynthesis. Closer inspection of TGF- $\beta 1$ and SMAD3 in 5-week-old POKO mice by RT-PCR surprisingly showed no significant increase in mRNA expression when compared to ob/ob mice (Figure 2). However we found increased significant immunostaining for TGF- $\beta$ in POKO pancreas sections at 16 weeks of age, starting to be present at 4 weeks in POKO mice (Figure 3).

Pathways associated to genes with lower expression in POKO compared to ob/ob islets were also identified by Fatiscan (Table 10 Figure 2) such as those relating to oxidative phosphorylation, sulphur metabolism reduction and fixation, mature onset diabetes in the young, ATP-binding cassette $(\mathrm{ABC})$ transporters and Type 1 and Type 2 diabetes. These results support the data obtained in our previous analysis between both the ob/ $\mathrm{ob}$ vs. WT and POKO vs. WT comparisons. Furthermore, we have also verified significantly decreased expression of ABCA1 and an isoform of NADH dehydrogenase (Ndufab1) in the islets of 5-week-old POKO compared with ob/ob mice by RT-PCR (Figure 2).
Carbohydrate responsive element-binding protein (Chrebp), casein kinase 1 (ck1) and insulin-like growth factor type 1 receptor (igfr1) pathways were the three highly expressed in Biocarta associated to genes with higher expression in POKO compared with ob/ob islets (data not shown).

FastiScan analysis identified 3 JasparTBS to be significantly (adj. p-value $\leq 0.05$ ) overrepresented in islets from POKO relative to the ob/ob mice. The list of genes regulated by the transcription factors Pax 2 and Arnt:Ahr were significantly expressed in POKO compared with ob/ob islets, while genes regulated by HOXA5 were down regulated and overrepresented in POKO islets (Table 11).

\section{Dysregulation of genes dependent on PPAR in POKO and ob/ob islets}

One of the pathways we found to be altered in FatiScan analysis between POKO vs. ob/ob was the PPAR pathway (Table 9). The expression of PPAR alpha and total PPAR gamma were decreased in the islets of POKO

Table 8 GO significant terms down-regulated in ob/ob vs. WT, without significant changes in POKO vs. WT mice

\begin{tabular}{|c|c|c|c|}
\hline Name & Term size & Odds ratio log & Adj. pvalue \\
\hline \multicolumn{4}{|l|}{ GO molecular function } \\
\hline L-glutamine transmembrane transporter activity (GO:0015186) & 5 & 4.55 & $1.27 \mathrm{E}-002$ \\
\hline \multicolumn{4}{|l|}{ GO cellular component } \\
\hline desmosome (GO:0030057) & 24 & 2.47 & 2.39E-004 \\
\hline apical junction complex (GO:0043296) & 132 & 1.82 & 1.17E-009 \\
\hline apicolateral plasma membrane (GO:0016327) & 134 & 1.8 & 1.17E-009 \\
\hline tight junction (GO:0005923) & 102 & 1.7 & $3.21 \mathrm{E}-006$ \\
\hline cell-cell junction (GO:0005911) & 219 & 1.4 & $2.54 \mathrm{E}-007$ \\
\hline cell junction (GO:0030054) & 540 & 0.88 & 1.57E-005 \\
\hline \multicolumn{4}{|l|}{ GO biological process } \\
\hline cholesterol biosynthetic process (G0:0006695) & 30 & 2.47 & $4.76 \mathrm{E}-004$ \\
\hline sterol biosynthetic process (GO:0016126) & 37 & 2.17 & 2.13E-003 \\
\hline tongue development (GO:0043586) & 12 & 3.16 & 3.09E-003 \\
\hline glutamine transport (GO:0006868) & 5 & 4.55 & $9,11 \mathrm{E}-003$ \\
\hline
\end{tabular}

GO significant terms down-regulated in islets from ob/ob vs. WT mice (adjusted p-value $\leq 0.05$ ), without significant changes in islets from POKO vs. WT mice. 
Table 9 KEGG significant terms up-regulated in POKO vs. ob/ob mice

\begin{tabular}{|c|c|}
\hline ID & Term \\
\hline mmu04740 & Olfactory transduction \\
\hline mmu03040 & Spliceosome \\
\hline mmu04810 & Regulation of actin cytoskeleton \\
\hline mmu04530 & Tight junction \\
\hline mmu04520 & Adherens junction \\
\hline mmu03050 & Proteasome \\
\hline mmu03010 & Ribosome \\
\hline mmu05219 & Bladder cancer \\
\hline mmu04512 & ECM-receptor interaction \\
\hline mmu05200 & Pathways in cancer \\
\hline mmu04670 & Leukocyte transendothelial migration \\
\hline mmu04115 & p53 signaling pathway \\
\hline mmu03020 & RNA polymerase \\
\hline mmu04020 & Calcium signaling pathway \\
\hline mmu00270 & Cysteine and methionine metabolism \\
\hline mmu00260 & Glycine, serine and threonine metabolism \\
\hline mmu00830 & Retinol metabolism \\
\hline mmu00240 & Pyrimidine metabolism \\
\hline mmu04510 & Focal adhesion \\
\hline mmu00900 & Terpenoid backbone biosynthesis \\
\hline mmu00100 & Steroid biosynthesis \\
\hline mmu00450 & Selenocompound metabolism \\
\hline mmu00480 & Glutathione metabolism \\
\hline mmu04012 & ErbB signaling pathway \\
\hline mmu04360 & Axon guidance \\
\hline mmu03420 & Nucleotide excision repair \\
\hline mmu04621 & NOD-like receptor signaling pathway \\
\hline mmu04144 & Endocytosis \\
\hline mmu04540 & Gap junction \\
\hline mmu00330 & Arginine and proline metabolism \\
\hline mmu04010 & MAPK signaling pathway \\
\hline mmu04062 & Chemokine signaling pathway \\
\hline mmu04110 & Cell cycle \\
\hline mmu00970 & Aminoacyl-tRNA biosynthesis \\
\hline mmu04350 & TGF-beta signaling pathway \\
\hline mmu00230 & Purine metabolism \\
\hline mmu03030 & DNA replication \\
\hline mmu00250 & Alanine, aspartate and glutamate metabolism \\
\hline mmu00561 & Glycerolipid metabolism \\
\hline mmu04060 & Cytokine-cytokine receptor interaction \\
\hline mmu00520 & Amino sugar and nucleotide sugar metabolism \\
\hline mmu00290 & Valine, leucine and isoleucine biosynthesis \\
\hline mmu00052 & Galactose metabolism \\
\hline mmu00040 & Pentose and glucuronate interconversions \\
\hline mmu03018 & RNA degradation \\
\hline mmu03320 & PPAR signaling pathway \\
\hline
\end{tabular}

KEGG significant terms up-regulated in islets from POKO vs. ob/ob mice (adjusted $\mathrm{p}$-value $\leq 0.05$ ) compared with ob/ob mice (Figure 2); however the expression of PPAR beta/delta were increased (Figure 2 and Additional file 1 Table S1). Furthermore, the expression of the three isoforms of the nuclear receptor Retinoic X receptor (RXR alpha, beta and gamma), heterodimers of PPARs, were differentially altered depending on the isoform as shown in the table. Most of the pathways analysed had increased or decreased expression of PPAR target genes as shown in Additional file 1 Table S1. However, gene expression of PPAR target genes involved in lipogenesis (SCD1, ME1, FADS2) and in cholesterol metabolism (CYP7A1, CYP8B1, LXRa and CYP27) were increased in POKO compared to ob/ob islets (Figure 2). Conversely, PPAR target genes involved in fatty acid oxidation (Ehhadh, Acaa1b, SCP2, Acox1, CPT1a, CPT1c and CPT2) were decreased suggesting these genes could be regulated by the PPAR $\gamma 2$ isoform, a pattern also observed with genes involved in adipocyte differentiation (Perilipin, aP2, adipoq, MMP-1) or gluconeogenesis (PEPCK, GyK, AQP7).

\section{Genome Wide candidate genes and early transcriptional response in pancreatic beta cells}

Recent genome-wide association studies have provided an important resource for furthering our understanding of type 2 diabetes disease mechanisms [5,9]. These published variants were all associated with insulin-secretory defects in the general population and show little if any relationship to insulin resistance. We have checked these genes in both our comparisons (See additional file 1 Figure S3). Although expression of Slc30A8 was not altered in the two comparisons in our microarray data, we found that expression of Slc30A8 detected by RTPCR was decreased in islets from POKO compared to $\mathrm{ob} / \mathrm{ob}$ mice and in islets from PPAR $\gamma 2 \mathrm{KO}$ compared to WT mice. Furthermore, using NSITE/Recognition of Regulatory motifs tool we found a PPAR conserved sequence motif in this gene suggesting this gene has a dependency on PPAR $\gamma$.

We also checked expression of NR4A3 (also called Neuron-derived orphan receptor (Nor) 1) by RT-PCR in our models. This is a novel candidate gene for $\beta$-cell function, which was not covered by the SNP arrays of the recent genome-wide association studies for type 2 diabetes mellitus [20]. Here we found significantly increased expression of NR4A3 in ob/ob and POKO islets when compared with WT and PPAR $\gamma 2 \mathrm{KO}$ islets, but no significant differences between the ob/ob and POKO islets (See Additional file 1 Figure S3).

Recent studies have shown that the Notch-regulated transcription factor neurogenin $3(\mathrm{Ngn} 3)$ is critical for 


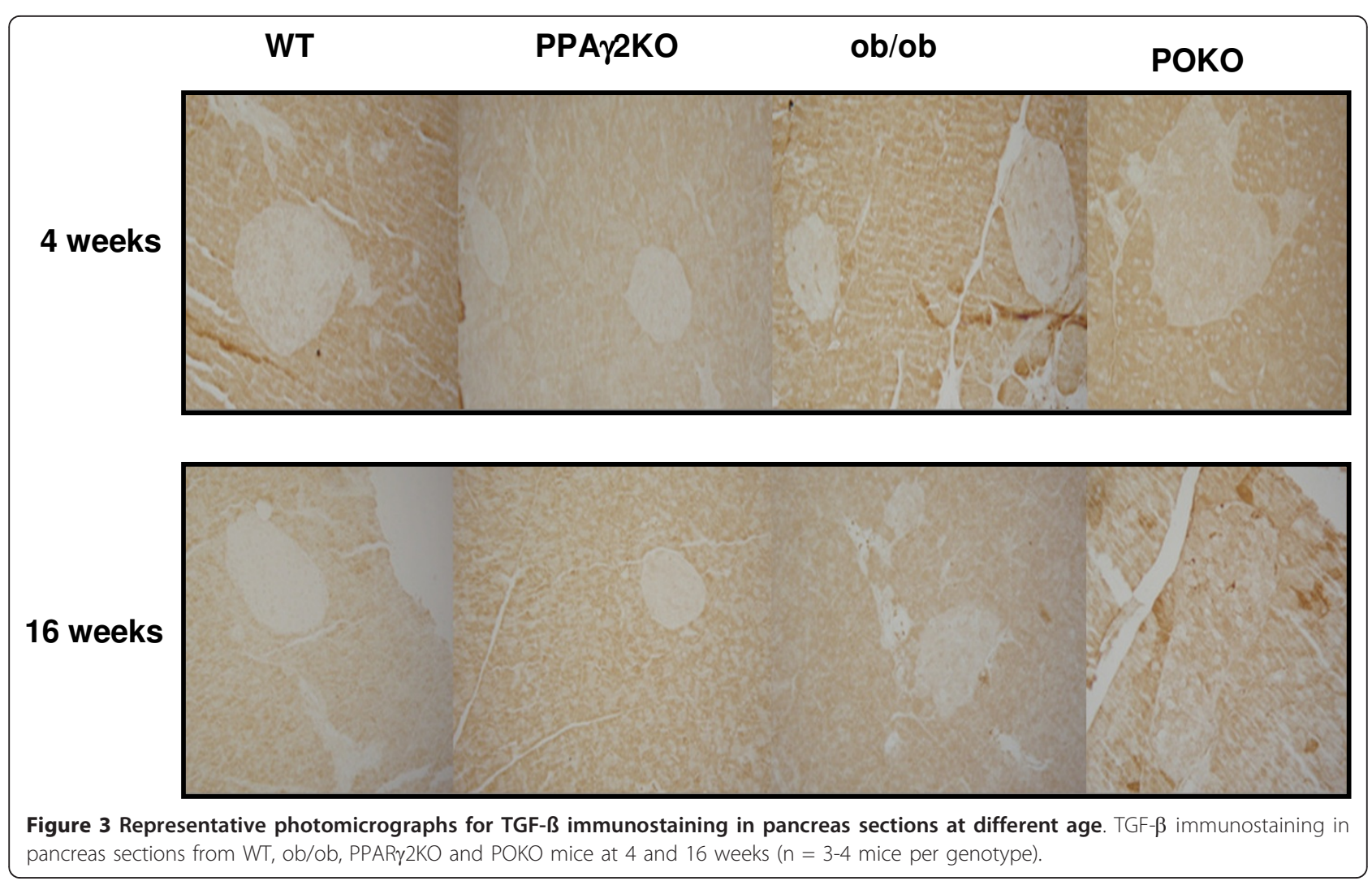

Table 10 KEGG significant down-regulated in POKO vs. ob/ob mice

\begin{tabular}{cc}
\hline ID & Term \\
\hline mmu00190 & Oxidative phosphorylation \\
mmu05016 & Huntington's disease \\
mmu05012 & Parkinson's disease \\
mmu04142 & Lysosome \\
mmu04270 & Vascular smooth muscle contraction \\
mmu04730 & Long-term depression \\
mmu04940 & Type I diabetes mellitus \\
mmu02010 & ABC transporters \\
mmu00510 & N-Glycan biosynthesis \\
mmu04612 & Antigen processing and presentation \\
mmu04720 & Long-term potentiation \\
mmu05330 & Allograft rejection \\
mmu04260 & Cardiac muscle contraction \\
mmu04070 & Phosphatidylinositol signaling system \\
mmu00920 & Sulfur metabolism \\
mmu05320 & Autoimmune thyroid disease \\
mmu04912 & GnRH signaling pathway \\
mmu04930 & Type II diabetes mellitus \\
mmu04914 & Progesterone-mediated oocyte maturation \\
mmu04950 & Maturity onset diabetes of the young \\
\hline
\end{tabular}

KEGG significant terms down-regulated in islets from POKO vs. ob/ob mice (adjusted p-value $\leq 0.05$ ). the development of endocrine cells of islets [21]. Ngn3 was increased in islets from ob/ob and POKO mice compared with those from PPAR $\gamma 2 \mathrm{KO}$ and WT, but with no significant differences between the former genotypes. From the current GWAS and metaanalysis in Europeans associated to adiposity loci [22], we identified increased NEGR1 expression in our microarray data between ob/ob and WT islets and lower expression in POKO when compared to ob/ob islets after analysis by RT-PCR.

\section{Discussion}

In this study we have used a gene expression microarray and a subsequent bioinformatic approach to identify new molecular mechanisms and pathways implicated in the expansion of pancreatic $\beta$-cells in the context of insulin

Table 11 Jaspar TFBS significant terms down-regulated in POKO vs. ob/ob mice

\begin{tabular}{cccc}
\hline Term & Term size & Odds ratio log & Adj pvalue \\
\hline Pax2 & 298 & 0.54 & $3.20 \mathrm{E}-02$ \\
Arnt::Ahr & 456 & 0.47 & $3.20 \mathrm{E}-02$ \\
HOXA5 & 168 & -0.74 & $2.88 \mathrm{E}-02$ \\
\hline
\end{tabular}

Jaspar Transcription Factor Binding Site (TFBS) significant terms downregulated in islets from POKO vs. ob/ob mice (adjusted p-value $\leq 0.05$ ). 
resistance. Using this technique and bioinformatic analysis we have investigated: 1) the overrepresentation of genes related to $\beta$-cell expansion under situations of insulin resistance in islets, 2 ) the genes differentially expressed in insulin resistant islets with and without the capacity of $\beta$ cell to expand, and 3) the overrepresentation of functional groups of genes differentially expressed previously to normal o defective expansion of $\beta$-cell mass.

We first examined genes that were upregulated in the islets of ob/ob compared to WT mice, expecting to identify pathways relevant to $\beta$-cell mass expansion for future comparison with the POKO mouse which is unable to expand its islets. We found that, at the age of 5 weeks, the ob/ob islets already exhibit induction of several pathways relating to cell proliferation and survival mechanisms. This response was not observed in POKO islets suggesting that these regulatory mechanisms are activated very early on before severe metabolic stress has developed, and that a failure to initiate these pathways is effectively contributing to the failure of the homeostatic control of $\beta$-cell mass in POKO islets. Specifically, POKO islets did not show the same induction of cyclin A2, B1, D1 and D3 observed in ob/ob islets, where in addition to their role in cell cycle progression, new data has revealed an emerging role of D-type cyclins in transcriptional regulation and cellular differentiation processes. There is also evidence from studies in 3T3-L1 cells that cyclin D3 acts as a ligand-dependent PPAR $\gamma$ coactivator and that its expression is increased throughout the adipocyte differentiation process [23]. Our results could therefore suggest that regulation of cyclinD3 is at least partly dependent on PPAR $\gamma$ which may be of relevance in the proliferative mechanisms of $\beta$-cell mass. Other universal genes previously shown to be increased during the expansion of the $\beta$ cell during obesity or pregnancy such as Birc5, Igf1r and Rasgrp1 also failed to increase in PPAR $\gamma$ deficient ob/ob islets (POKO vs. WT) further suggesting an inability of POKO islets to proliferate at a young age.

We were interested in identifying a putative molecular mechanism that could induce the pancreatic islet dysfunction in POKO mice. Our experimental design allowed the identification of pathways associated with the normal adaptation of islets to obesity induced insulin resistance (comparison ob/ob vs. WT) and pathways associated with failure in this response (comparison POKO vs. WT). We have identified genes associated with canonical pathways of Autoimmune Thyroid Disease Signalling, Allograft Rejection Signalling and Type 1 Diabetes Mellitus Signalling are upregulated in ob/ob vs. WT islets. This was associated with a significant increase of genetic programmes related to inflammatory disease, inflammatory response and immunological disease. It is well established that inflammation and fibrosis are processes preceding the deterioration of pancreatic islet structure. Molecules from MHCII (HLA-D, HLAA, HLA-B) and other molecules such as CD80/86, which are involved in the antigen presentation signalling were increased in ob/ob relative to WT islets, with no significant changes in the islets of POKO vs. WT, suggesting that their involvement in remodelling is linked to $\beta$-cell mass expansion. As these pathways are activated in ob/ob islets and not in POKO islets, and that this is occurring very early before ob/ob islets fail, we speculate that this immune and inflammatory response may in fact be a physiological response, initiating or enabling a mechanism of remodelling or adaptation in order for the $\beta$-cell mass to expand. Thus it is conceivable that these changes are part of an adaptive response required under metabolic stress as occurs in ob/ob mice, possibly involving signalling via PPAR $\gamma$.

Our FatiScan analysis showed that TGF- $\beta /$ Smad signaling pathway was significantly increased in POKO compared to ob/ob islets, which is supported by increased pancreatic staining of TGF- $\beta$ in POKO islets at 4 and 16 weeks of age. It has already been shown in other organs such as kidney that stimulation of fibrotic processes could be mediated, at least in part, by a down-regulation of PPAR $\gamma$ that can favour an up-regulation of the TGF- $\beta /$ Smad signalling pathway $[24,25]$. Genes such as TGF- $\beta 1$, its receptors type I and II and SMAD2/3/4, also implicated in apoptosis and cell cycle arrest through this pathway were increased in POKO islets compared to ob/ob islets, suggesting that specific profibrotic and apoptotic genes could also be involved in the failure of $\beta$-cell expansion in POKO islets.

Two genes, perforin 1 and granzyme $\mathrm{B}$ which are required for the direct recognition of the cells [26] were also up regulated in our ob/ob vs. WT comparison. The dominant role of the perforin/granzyme pathway in $\beta$-cell destruction in type 1 diabetes and allogeneic islet graft rejection makes this pathway an important target for future therapies for type 1 diabetes. However our results and the suggested new role of these molecules in inflammation also suggests that they could be new targets for treatments of type 2 diabetes, as part of their role includes the adaptation of the $\beta$-cell to insulin resistance. Indeed they could contribute to the remodelling mechanisms enabling the necessary expansion of the pancreatic $\beta$-cell by controlling apoptosis in a PPAR $\gamma$ dependent pathway. Supporting this idea, we have found that the perforin promoter has a PPAR response element and that POKO islets lack this immune response, further supporting its role facilitating the remodelling adaptation in response to insulin resistance. Globally considered our data indicate that PPAR $\gamma$-ablated islets (POKO) may have decreased capacity for remodelling and an exacerbated proapoptotic response ultimately leading to their failure. 
Besides an increased $\beta$-cell mass during the adaptation to insulin resistance, the most immediate response is the optimisation of the insulin secretion. The data from this study showed that cholesterol-induced impairment of $\beta$-cell function could occur in POKO islets as happens in other models [27]. It has already been shown that Ldlr-/- knockout mice with $\beta$-cell-specific ATPbinding cassette transporter A1 (ABCA1) deficiency showed increased islet cholesterol content and $\beta$-cell dysfunction, suggesting that cholesterol efflux through $A B C A 1$ is a critical regulator of islet cholesterol content and $\beta$-cell function [28]. Functional analysis using FatiScan and our RT-PCR results revealed increased expression of genes related to cholesterol and sterol biosynthesis and decreased expression of ATP-binding cassette $(\mathrm{ABC})$ transporters in POKO compared with $\mathrm{ob} / \mathrm{ob}$ islets. Also rosiglitazone, an activator of the peroxisome proliferator-activated receptor-gamma, requires $\beta$-cell ABAC1 for its beneficial effects on glucose tolerance. It has been suggested that elevated $\beta$-cell cholesterol levels may impair insulin secretion by promoting the dimerisation of neuronal NO synthase (nNOS), which downregulates glucokinase (GK), thus impairing glucose sensing. This will agree with our previous observation showing that GK is downregulated in POKO compared with ob/ob islets [17]. Moreover, it has been suggested that cholesterol also inhibits steps in insulin exocytosis and that ABCA1 could have other independent effects on insulin secretion. Here we show that granulophilin is downregulated in POKO islets and its expression depends on PPAR $\gamma$ similarly to GK. Thus we suggest that PPAR $\gamma$ could play a main role determining the cholesterol flux and its toxicity on the islet insulin secretion machinery under insulin resistance conditions.

Another pathway down regulated in POKO in comparison to ob/ob islets was oxidative phosphorylation. Different isoforms of Cytochrome c oxidase and NADH dehydrogenase were downregulated in POKO compared to ob/ob islets suggesting impaired complexes of the mitochondrial oxidative phosphorylation system in POKO islets could contribute to the failure of their islets. It has been shown recently in human islets and cell lines [29], that increased levels of nitrogen species may interact with the insulin exocitosis mechanism. From our previous data, we did not observe increased levels of ROS in POKO mice at this age; however nitrogen species under pathophysiological conditions such as chronic hyperglycemia could result in insulin secretion dysfunction in POKO islets.

Actin cytoskeleton remodelling is known to be involved in glucose-stimulated insulin secretion (GSIS). Cell-cell contacts mediated by intercellular junctions are crucial for proper insulin secretion in the endocrine pancreas. FatiScan analysis found that the tight junction, adherens junction and focal adhesion pathways were increased in POKO compared to ob/ob islets. In fact expression of Actin 1 alpha, which is involved in focal adhesion, was increased in POKO islets. Of note activation of actin cytoskeleton could result in increased fibrosis in the islets of POKO mice in a process facilitated by TGF- $\beta /$ Smad activation as has been similarly shown in liver fibrosis [30].

Genome-wide association studies (GWAS) have had success in identifying loci that are involved in common diseases such us diabetes and interestingly some locus were linked specifically with T2D. Mouse models offer a good tool to help to take data from GWAS studies further investigating the function of associated genes in vivo. We further investigated some of these T2D susceptibility loci identified thorough GWAS in our models. We found only significant dowregulation in GK and SLC30A8 in POKO in comparison to ob/ob islets, both dependent on PPAR $\gamma$ expression. Specific $\beta$-cell inactivation of SLC30A8 in mouse results in glucose intolerance [31] and recently published meta-analysis results revealed a significant association between the rs13266634 C/T polymorphism of SLC30A8 and T2DM and IGT [32]. Our results suggest that SLC30A8 might therefore have a role in expansion of the $\beta$-cell and benefit from PPAR $\gamma$ agonists in the treatment of type 2 diabetes.

\section{Conclusions}

Using transcriptome tools and mouse models of insulin resistance, in this study we show: a) that mechanisms of proliferation and survival signals were downregulated in POKO islets from an early age, b) we also identified new pathways that could be involved in the adaptation of the $\beta$-cell to insulin resistance during obesity and that they are defective in PPAR $\gamma$-deficient ob/ob islets. Our results indicate that early stages of $\beta$-cell mass expansion are associated with activation of an inflammatory immune response that could facilitate the necessary remodeling while preventing activation of an apoptotic cascade. Other potential relevant pathogenic mechanisms modulating $\beta$-cell mass include cholesterol toxicity, TGF- $\beta$ /Smad pathway-induced apoptosis/fibrosis and defective oxidative phosphorylation. As the pathways identified in our POKO islets are involved in the failure of $\beta$-cell function, our results indicate an important role of PPAR $\gamma$ in islets, modulating the adaptive response of $\beta$-cell mass to increased metabolic demands imposed by obesity and insulin resistance.

\section{Methods}

Animal care

Animals were housed in a temperature-controlled room (20-22 8C) with 12-h light/dark cycles. Food and water 
were available ad libitum unless noted. All animal protocols used in this study were approved by the UK Home Office and the University of Cambridge and by Ethical and Veterinary committees of Rey Juan Carlos University in Spain.

\section{Isolation and culture of pancreatic islets}

The pancreas was injected, though the bile duct, with cold Hank's solution containing $0.4 \%(\mathrm{w} / \mathrm{v})$ collagenase $\mathrm{P}$ (Roche Biochemicals). The pancreas was removed, digested for 8 minutes, and islets were collected by hand picking. Isolated islets were cultured overnight in cell medium (RPMI 1640 with $10 \% \mathrm{FBS}$, and $100 \mathrm{UI} / \mathrm{ml}$ penicillin, $100 \mu \mathrm{g} / \mathrm{ml}$ streptomycin), at $37^{\circ} \mathrm{C}$, in $5 \% \mathrm{CO} 2$ in air. For RNA extraction, islets were used on the day after isolation.

\section{RNA isolation and purification}

An average of 25-50 islets were used per sample and total RNA was extracted according to the manufacturer's instructions. Each sample was purified using the RNeasy ${ }^{\circledR}$ Mini kit (Qiagen Ltd, Crawley, UK). RNA was quantified using a NanoDrop ${ }^{\circledR}$ ND1000 spectrophotometer V 3.5.2 (NanoDrop Technologies, Wilmington, DE). RNA quality was subsequently assessed using the 28S:18S ratio running the samples on a denaturing agarose gel. The 2:1 ratio (28S:18S) indicated that the RNA was intact.

\section{Sample labelling}

One-Color Microarray-Based Gene Expression Analysis Protocol (Agilent Technologies, Palo Alto, CA, USA) was used to amplify and label RNA. A pool of 3-4 mice were used per each microarray and 3 microarrays were used per each genotype. Briefly, $400 \mathrm{ng}$ of total RNA from WT, PPAR $22 \mathrm{KO}, \mathrm{ob} / \mathrm{ob}$ and POKO mice, were reverse transcribed using $\mathrm{T} 7$ promoter primer and the Moloney murine leukemia virus (MMLV) reverse transcriptase. cDNA was then converted to anti-sense RNA (aRNA) by using T7 RNA polymerase that amplifies target material and incorporates cyanine 3 (Сy3)-labeled CTP simultaneously.

\section{Sample hybridization and image analysis}

Samples were hybridized to a Whole Mouse Genome Microarray 4x44K (G4122F, Agilent Technologies). 1.65 micrograms of Cy3-labeled aRNA were hybridized for 17 hours at $65^{\circ} \mathrm{C}$ in an Agilent hybridization oven (G2545A, Agilent Technologies) set to $10 \mathrm{rpm}$ in a final concentration of 1x GEx Hybridization Buffer HI-RPM (Agilent Technologies). Arrays were washed and dried out using a centrifuge according to manufacturer's instructions (One-Color Microarray-Based Gene Expression Analysis, Agilent Technologies). Arrays were scanned at $5 \mathrm{~mm}$ resolution on an Agilent DNA Microarray Scanner (G2565BA, Agilent Technologies) using the default settings for $4 \mathrm{x} 44 \mathrm{k}$ format one-color arrays. Images provided by the scanner were analyzed using Feature Extraction software v10.1.1.1 (Agilent Technologies).

\section{Quality control}

Based on statistical outliers criteria implemented in the Bioconductor package "ArrayQualityMetrics" there were no statistical outliers in terms of MA plots, dendrogram or boxplots.

\section{Statistical analysis}

For the normalization, Agilent Processed Signal (Agilent Feature Extraction Software) was standardized across arrays using quantile normalization [33].

Differential gene expression was carried out using the limma [34] package from Bioconductor. This approach fits a linear model to all data considering as fixed effect the type of mice and using the array as blocking variable. Limma calculates moderated t-statistics, adding to the error term some information on the variance of all genes, solving the typical microarray problem of small sample size ( 2 in one of the experimental groups). Multiple testing adjustment of $\mathrm{p}$-values was done according to Benjamini and Hochberg methodology [35].

The microarrays data of this study have been deposited in the Gene Expression Omnibus database under accession number GSE33647.

\section{Ingenuity Pathway Analysis}

Functional and Canonical Pathway analyses of specific gene datasets were generated through the use of Ingenuity Pathway Analysis (Ingenuity Systems ${ }^{\circledR}$, http://www. ingenuity.com).

The Functional analysis identified functions and/or diseases that were most significant to the dataset. Genes from the dataset that were associated with biological functions and/or diseases in the Ingenuity knowledge base were considered for the analysis. B-H Multiple Testing Correction p-value test was used to calculate a p-value determining the probability that each biological function and/or disease assigned to the data set is due to chance alone.

Genes associated with a canonical pathway in the Ingenuity knowledge database were considered for the analysis. The significance of the association between the dataset and the canonical pathway was measured in two ways: 1) A ratio of the number of genes from the dataset that map to the pathway divided by the total number of molecules that exist in the canonical pathway is displayed. 2) B-H Multiple Testing Correction p-value test was used to calculate a $\mathrm{p}$-value determining the 
probability that the association between the genes in the dataset and the canonical pathway is explained by chance alone. IPA identified significant networks, top functions and canonical pathways associated with the differentially expressed genes for each comparison analyzed.

\section{FatiGO and FatiScan analysis}

Enrichment analysis and gene set analysis was carried out for the Gene Ontology terms, InterPro terms and for the KEGG Pathways using FatiGO [36] and FatiScan [37] integrated in Babelomics suite [38].

FatiGO is a procedure to extract several functional terms as Gene Ontology (GO) terms, InterPro annotation or KEGG Pathways that are significantly over-or under-represented in sets of genes within the context of a genome-scale experiment. This resource is used to detect relevant functional terms for a group of genes with respect to a set of genes of reference (typically the rest of genes). The terms are considered to be relevant by the application of a Fisher's exact test that considers the multiple-testing nature of the statistical contrast performed.

FatiScan is a gene set analysis that detects significantly up-or down-regulated blocks of functionally related genes in lists of genes ordered by differential expression. FatiScan can search blocks of genes that are functionally related by different criteria such as gene ontology terms, Kyoto Encyclopedia of Genes and Genomes pathways, and others. The core of the method proposed is based on an algorithm to test whether a set of genes, labeled with terms (biological information), contain significant enrichments on one or several of these terms with respect to another set of genes of reference. FatiScan uses a Fisher's exact test for $2 \times 2$ contingency tables for comparing two groups of genes and extracting a list of GO terms whose distribution among the groups is significantly different. Given that many GO terms are simultaneously tested, the results of the test are corrected for multiple testing to obtain an adjusted $\mathrm{p}$-value. FatiScan returns adjusted p-values based on False Discovery Rate (FDR) method [39,40].

$\mathrm{GO}$ and InterPro annotation for the genes in the microarray where taken from Ensembl 56 release and KEGG Pathways from the KEGG web page.

\section{RNA preparation and real-time quantitative PCR for validation of the microarray}

Selected cDNA samples $(n=8-11)$ were quantified by real time quantitative PCR (qRT-PCR). Total RNA was isolated from islets samples according to the manufacturer's instructions following same protocols used for microarray RNA samples. Complimentary DNA was generated from $500 \mathrm{ng}$ of RNA using M-MLV reverse transcriptase and master mix (Promega) in a $20 \mu \mathrm{l}$ reaction with $2.5 \mathrm{mM} \mathrm{MgCl} 2,1.25 \mathrm{mM}$ dNTPs and $5 \mu \mathrm{g} / \mathrm{ml}$ random hexamers at $37^{\circ} \mathrm{C}$ for 1 hour. cDNA was diluted 75 fold and $5 \mu$ l of diluted cDNA was used in a $12 \mu \mathrm{l}$ real time PCR reaction using TaqMan primers and probes or SYBR green reagent (Applied Biosystems) according to manufacturers instructions. Reactions were run in duplicate for each sample and quantified in the ABI Prism 7900 sequence detection system (Applied Biosystems). Data was normalised to $18 \mathrm{~s}$ rRNA. Primer sequences are shown in Additional file 1 Table S2.

\section{Immunohistochemistry of TGF-beta}

Fixed tissue sections $(4 \mu \mathrm{m})$ were dehydrated by graded ethanol's and xylene, and then embedded in paraffin (23 sections per animal, 3-4 animal per group). The sections were deparaffinized and rehydrated. Sections were incubated with anti-TGF- $\beta$ (SantaCruz Biotechnology, INC.). Sections were incubated with a biotinylated antiIgG (Vector Laboratories) and incubated with the avidin-biotin-peroxidase complex (Vector Laboratories). 3, 3'-diaminobenzidine (DAB) substrate (Sigma-Aldrich ${ }^{\circledR}$ ) was used as the chromogen. Some samples were incubated without primary antibody as negative controls. The stained sections were imaged with a light microscope Zeiss Standard 25.

\section{Additional material}

Additional file 1: Figure S1 - GO Cellular Component significant terms. GO Cellular Component significant terms (adjusted p-value $\leq$ 0.05 ) down-regulated in ob/ob vs. WT, without significant changes in POKO vs. WT. Figure S2 - GO Biological Process significant terms. GO Biological Process significant terms (adjusted p-value $\leq 0.05$ ) downregulated in ob/ob vs. WT, without significant changes in POKO vs. WT. Figure S3 - Real time qRT-PCR results form genes from GWAS studies to validate microarrays data. Islet gene expression from 5week-old female WT, ob/ob, PPAR $\gamma 2 \mathrm{KO}$ and POKO mice ( $\mathrm{n}=8-11$ mice per genotype). ${ }^{*} p<0.05$ POKO vs. ob/ob. Table S1 - PPAR signalling pathway in POKO vs. ob/ob mice. Genes from PPAR signalling pathway (adjusted $p$-value $\leq 0.05$ ) in islets from POKO vs. ob/ob mice. Table S2 - Table of primers and probes sequences used in RT-PCR validation. Sequences of primers and probes (Syber-Green and Taqman) used in RT-PCR validation.

\section{Acknowledgements}

We thank Janice Carter, Daniel Hart, Sergio Ferreiro and Davinia Hernandez for their work. We thank the funding bodies that have support research within our laboratories leading to this work: Diabetes UK, the MRC programme grant, MCINN BFU2009-10006 and BFU2008-04901-C03-03, CCG10-URJC/BIO-560 and L'Oreal-Unesco.

\section{Author details}

${ }^{1}$ Universidad Rey Juan Carlos. Dpto. de Bioquímica, Fisiología y Genética

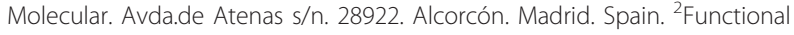
Genomics Node, National Institute for Bioinformatics. Centro de Investigacion Prıncipe Felipe, Camino de las Moreras, 46012 Valencia, Spain. ${ }^{3}$ Genomics Unit. CNIC (Centro Nacional de Investigaciones Cardiovasculares). Fernández Almagro, 3. 28029 Madrid, Spain. ${ }^{4}$ University of Cambridge 
Metabolic Research Laboratories. Institute of Metabolic Science, NIHR Cambridge Biomedical Research Centre Level 4. Addenbrooke's Hospital, Hills Rd. Cambridge CB2 OQQ. UK.

\section{Authors' contributions}

YV, MR, AVP and GMG designed the experiment. YV, CMG, Al, IV, MC and GMG participated in the collection of samples. $Y$, IV, MC performed the RNA extractions. $Y$ and $M C$ performed the real time qRT-PCR experiments. FGG, JD, SC and AD were responsible for the bioinformatics. FGG and SC performed functional analysis of the data. W, MR, FGG and SC assisted with manuscript preparation. AVP and GMG wrote the paper. GMG coordinated and supervised the project. All authors read and approved the final manuscript.

\section{Competing interests}

The authors declare that they have no competing interests.

Received: 28 July 2011 Accepted: 30 December 2011

Published: 30 December 2011

\section{References}

1. Martin BC, Warram JH, Krolewski AS, Bergman RN, Soeldner JS, Kahn CR: Role of glucose and insulin resistance in development of type 2 diabetes mellitus: results of a 25-year follow-up study. Lancet 1992, 340(8825):925-929.

2. Prentki $\mathrm{M}$, Nolan $\mathrm{CJ}$ : Islet beta cell failure in type 2 diabetes. J Clin Invest 2006, 116(7):1802-1812.

3. Rieck $\mathrm{S}$, Kaestner $\mathrm{KH}$ : Expansion of beta-cell mass in response to pregnancy. Trends Endocrinol Metab 2010, 21(3):151-158.

4. Doria A, Abumrad NA: Genome-wide associations and metabolic disease: the big revolution. Curr Opin Clin Nutr Metab Care 2008, 11(4):363-365.

5. Saxena R, Voight BF, Lyssenko V, Burtt NP, de Bakker PI, Chen H, Roix JJ, Kathiresan S, Hirschhorn JN, Daly MJ, et al: Genome-wide association analysis identifies loci for type 2 diabetes and triglyceride levels. Science 2007, 316(5829):1331-1336.

6. Scott L, Mohlke KL, Bonnycastle LL, Willer CJ, Li Y, Duren WL, Erdos MR, Stringham HM, Chines PS, Jackson AU, et al: A genome-wide association study of type 2 diabetes in Finns detects multiple susceptibility variants. Science 2007, 316(5829):1341-1345.

7. Sladek R, Rocheleau G, Rung J, Dina C, Shen L, Serre D, Boutin P, Vincent D, Belisle A, Hadjadj $\mathrm{S}$, et al: A genome-wide association study identifies novel risk loci for type 2 diabetes. Nature 2007, 445(7130):881-885.

8. Steinthorsdottir V, Thorleifsson G, Reynisdottir I, Benediktsson R, Jonsdottir T, Walters GB, Styrkarsdottir U, Gretarsdottir S, Emilsson V, Ghosh $S$, et al: A variant in CDKAL1 influences insulin response and risk of type 2 diabetes. Nat Genet 2007, 39(6):770-775.

9. Zeggini E, Weedon MN, Lindgren CM, Frayling TM, Elliott KS, Lango H, Timpson NJ, Perry JR, Rayner NW, Freathy RM, et al: Replication of genome-wide association signals in UK samples reveals risk loci for type 2 diabetes. Science 2007, 316(5829):1336-1341.

10. Spiegelman BM: PPAR-gamma: adipogenic regulator and thiazolidinedione receptor. Diabetes 1998, 47(4):507-514.

11. Rosen ED, Kulkarni RN, Sarraf P, Ozcan U, Okada T, Hsu CH, Eisenman D, Magnuson MA, Gonzalez FJ, Kahn CR, et al: Targeted elimination of peroxisome proliferator-activated receptor gamma in beta cells leads to abnormalities in islet mass without compromising glucose homeostasis. Mol Cell Biol 2003, 23(20):7222-7229.

12. Bruning JC, Winnay J, Bonner-Weir S, Taylor SI, Accili D, Kahn CR: Development of a novel polygenic model of NIDDM in mice heterozygous for IR and IRS-1 null alleles. Cell 1997, 88(4):561-572.

13. Hull RL, Kodama K, Utzschneider KM, Carr DB, Prigeon RL, Kahn SE: Dietaryfat-induced obesity in mice results in beta cell hyperplasia but not increased insulin release: evidence for specificity of impaired beta cell adaptation. Diabetologia 2005, 48(7):1350-1358.

14. Parsons JA, Brelje TC, Sorenson RL: Adaptation of islets of Langerhans to pregnancy: increased islet cell proliferation and insulin secretion correlates with the onset of placental lactogen secretion. Endocrinology 1992, 130(3):1459-1466.

15. Sachdeva MM, Stoffers DA: Minireview: Meeting the demand for insulin: molecular mechanisms of adaptive postnatal beta-cell mass expansion. Mol Endocrinol 2009, 23(6):747-758.
16. Medina-Gomez G, Gray SL, Yetukuri L, Shimomura K, Virtue S, Campbell M, Curtis RK, Jimenez-Linan M, Blount M, Yeo GSH, et al: PPAR gamma 2 prevents lipotoxicity by controlling adipose tissue expandability and peripheral lipid metabolism. Plos Genetics 2007, 3(4):e64.

17. Medina-Gomez G, Yetukuri L, Velagapudi V, Campbell M, Blount M, Jimenez-Linan M, Ros M, Oresic M, Vidal-Puig A: Adaptation and failure of pancreatic beta cells in murine models with different degrees of metabolic syndrome. Disease Models \& Mechanisms 2009, 2:(11-12):582-592.

18. Medina-Gomez G, Gray SL, Yetukuri L, Shimomura K, Virtue S, Campbell M, Curtis RK, Jimenez-Linan M, Blount M, Yeo GS, et al: PPAR gamma 2 prevents lipotoxicity by controlling adipose tissue expandability and peripheral lipid metabolism. PLoS Genet 2007, 3(4):e64.

19. Cozar-Castellano I, Fiaschi-Taesch N, Bigatel TA, Takane KK, Garcia-Ocana A, Vasavada R, Stewart AF: Molecular control of cell cycle progression in the pancreatic beta-cell. Endocr Rev 2006, 27(4):356-370.

20. Weyrich P, Staiger H, Stancakova A, Schafer SA, Kirchhoff K, Ullrich S, Ranta F, Gallwitz B, Stefan N, Machicao F, et al: Common polymorphisms within the NR4A3 locus, encoding the orphan nuclear receptor Nor-1, are associated with enhanced beta-cell function in non-diabetic subjects. BMC Med Genet 2009, 10:77.

21. Gradwohl G, Dierich A, LeMeur M, Guillemot F: neurogenin3 is required for the development of the four endocrine cell lineages of the pancreas. Proc Natl Acad Sci USA 2000, 97(4):1607-1611.

22. Willer CJ, Speliotes EK, Loos RJ, Li S, Lindgren CM, Heid IM, Berndt SI, Elliott AL, Jackson AU, Lamina $C$, et al: Six new loci associated with body mass index highlight a neuronal influence on body weight regulation. Nat Genet 2009, 41(1):25-34.

23. Sarruf DA, lankova I, Abella A, Assou S, Miard S, Fajas L: Cyclin D3 promotes adipogenesis through activation of peroxisome proliferatoractivated receptor gamma. Mol Cell Biol 2005, 25(22):9985-9995.

24. Miana M, de Las Heras N, Rodriguez C, Sanz-Rosa D, Martin-Fernandez B, Mezzano S, Lahera V, Martinez-Gonzalez J, Cachofeiro V: Effect of eplerenone on hypertension-associated renal damage in rats: potential role of peroxisome proliferator activated receptor gamma (PPARgamma). J Physiol Pharmacol 2011, 62(1):87-94.

25. Wang W, Liu F, Chen N: Peroxisome proliferator-activated receptorgamma (PPAR-gamma) agonists attenuate the profibrotic response induced by TGF-beta1 in renal interstitial fibroblasts. Mediators Inflamm 2007, 2007:62641.

26. Thomas HE, Trapani JA, Kay TW: The role of perforin and granzymes in diabetes. Cell Death Differ 2010, 17(4):577-585.

27. Bonfleur ML, Vanzela EC, Ribeiro RA, de Gabriel Dorighello G, de Franca Carvalho CP, Collares-Buzato CB, Carneiro EM, Boschero AC, de Oliveira HC: Primary hypercholesterolaemia impairs glucose homeostasis and insulin secretion in low-density lipoprotein receptor knockout mice independently of high-fat diet and obesity. Biochim Biophys Acta 2010, 1801(2):183-190.

28. Joyce CW, Wagner EM, Basso F, Amar MJ, Freeman LA, Shamburek RD, Knapper $C L$, Syed J, Wu J, Vaisman BL, et al: $A B C A 1$ overexpression in the liver of LDLr-KO mice leads to accumulation of pro-atherogenic lipoproteins and enhanced atherosclerosis. J Biol Chem 2006, 281(44):33053-33065.

29. Wiseman DA, Kalwat MA, Thurmond DC: Stimulus-induced Snitrosylation of Syntaxin 4 impacts insulin granule exocytosis. J Biol Chem 2011, 286(18):16344-16354

30. Pan X, Dai Y, Li X, Niu N, Li W, Liu F, Zhao Y, Yu Z: Inhibition of arsenic induced-rat liver injury by grape seed exact through suppression of NADPH oxidase and TGF-beta/Smad activation. Toxicol Appl Pharmacol 2011, 254(3):323-31.

31. Wijesekara N, Dai FF, Hardy AB, Giglou PR, Bhattacharjee A, Koshkin V, Chimienti F, Gaisano HY, Rutter GA, Wheeler MB: Beta cell-specific Znt8 deletion in mice causes marked defects in insulin processing, crystallisation and secretion. Diabetologia 2010, 53(8):1656-1668.

32. Xu K, Zha M, Wu X, Yu Z, Yu R, Xu X, Chen H, Yang T: Association between rs13266634 C/T polymorphisms of solute carrier family 30 member 8 (SLC30A8) and type 2 diabetes, impaired glucose tolerance, type 1 diabetes-a meta-analysis. Diabetes Res Clin Pract 2011, 91(2):195-202.

33. Bolstad BM, Irizarry RA, Astrand M, Speed TP: A comparison of normalization methods for high density oligonucleotide array data based on variance and bias. Bioinformatics 2003, 19(2):185-193. 
34. Wettenhall JM, Smyth GK: limmaGUI: a graphical user interface for linear modeling of microarray data. Bioinformatics 2004, 20(18):3705-3706.

35. Hochberg Y, Benjamini Y: More powerful procedures for multiple significance testing. Stat Med 1990, 9(7):811-818.

36. Al-Shahrour F, Diaz-Uriarte R, Dopazo J: FatiGO: a web tool for finding significant associations of Gene Ontology terms with groups of genes. Bioinformatics 2004, 20(4):578-580.

37. Al-Shahrour F, Minguez P, Tarraga J, Medina I, Alloza E, Montaner D, Dopazo J: FatiGO +: a functional profiling tool for genomic data. Integration of functional annotation, regulatory motifs and interaction data with microarray experiments. Nucleic Acids Res 2007, , 35 Web Server: W91-96

38. Medina I, Carbonell J, Pulido L, Madeira SC, Goetz S, Conesa A, Tarraga J, Pascual-Montano A, Nogales-Cadenas R, Santoyo J, et al: Babelomics: an integrative platform for the analysis of transcriptomics, proteomics and genomic data with advanced functional profiling. Nucleic Acids Res 2010, 38 Web Server: W210-213.

39. Benjamini $Y$, Hochberg Y: Controlling the False Discovery Rate: A Practical and Powerful Approach to Multiple Testing. Journal of the Royal Statistical Society 1995, 57(1):289-300

40. Benjamini Y, Drai D, Elmer G, Kafkafi N, Golani I: Controlling the false discovery rate in behavior genetics research. Behav Brain Res 2001, 125(12):279-284.

Pre-publication history

The pre-publication history for this paper can be accessed here: http://www.biomedcentral.com/1755-8794/4/86/prepub

doi:10.1186/1755-8794-4-86

Cite this article as: Vivas et al.: Early peroxisome proliferator-activated receptor gamma regulated genes involved in expansion of pancreatic beta cell mass. BMC Medical Genomics 2011 4:86.

\section{Submit your next manuscript to BioMed Central and take full advantage of:}

- Convenient online submission

- Thorough peer review

- No space constraints or color figure charges

- Immediate publication on acceptance

- Inclusion in PubMed, CAS, Scopus and Google Scholar

- Research which is freely available for redistribution

Submit your manuscript at www.biomedcentral.com/submit 